\title{
Change versus stability: are protected areas particularly pressured by global land cover change?
}

\author{
Carlos António Guerra - Isabel M. D. Rosa $\cdot$ Henrique M. Pereira
}

Received: 26 November 2018/ Accepted: 5 October 2019/Published online: 18 October 2019

(C) The Author(s) 2019

\begin{abstract}
Context Land cover change is a global multi-scale process affecting ecosystems, with potential implications for ecological processes and for the biological communities that support them. Land cover changes are especially relevant for protected areas where longterm ecosystem stability is a critical aspect of protecting and maintaining high levels of biodiversity and ecosystem functions.

Objectives To understand the extent of land cover change impact on global ecosystem stability of protected areas across time and space.

Methods Here we analysed 23 years of global spatial and temporal distribution of land cover change its
\end{abstract}

Electronic supplementary material The online version of this article (https://doi.org/10.1007/s10980-019-00918-4) contains supplementary material, which is available to authorized users.

\section{A. Guerra $(\bowtie) \cdot$ H. M. Pereira}

Institute of Biology, Martin Luther University Halle-

Wittenberg, Am Kirchtor 1, 06108 Halle (Saale),

Germany

e-mail: carlos.guerra@idiv.de

C. A. Guerra - H. M. Pereira

German Centre for Integrative Biodiversity Research

(iDiv), Halle-Jena-Leipzig, Deutscher Platz 5E,

04103 Leipzig, Germany

I. M. D. Rosa

School of Natural Sciences, Bangor University, Bangor,

Gwynedd LL57 2DG, United Kingdom occurrence within protected areas. We investigated whether higher land cover change rates occurred inside or outside protected areas, identified the main type of changes, and their distribution by UN region. Results Our results show that from 1992 to 2015, $4.89 \%$ of the world's land surface changed from one land cover to another, with $97.9 \%$ of this change persisting until the end of the time period. We found that regions with higher land cover change, tend to have a higher incidence of change close to protected areas, suggesting a spillover effect on these areas. Also, the proportion of change inside and outside protected areas varied considerably across UN Regions.

Conclusions Our results suggest that to reach current global conservation targets, it is not enough to increase the targets of protected area coverage. Instead, governments and conservation management agencies should account for regional specificities, and pay attention to the territories surrounding protected areas to develop strategies to reduce spillover effects.

Keywords Land degradation · Global · Ecosystem change $\cdot$ Landscape impacts $\cdot$ Spillover effects 


\section{Introduction}

Land cover change is a global multi-scale process affecting ecosystems and their ecological features (Foley et al. 2005; Pereira et al. 2012; Small and Sousa 2016). Depending on their extent and intensity, changes in land cover can represent a complete shift of existing ecosystems [e.g. deforestation in the Amazon (Levine et al. 2016)] or more long-term ecological adjustments [e.g. 1 and abandonment followed by ecological succession (Benjamin et al. 2005)]. Characterizing these processes at the global scale entails several challenges according to regional and macro-bioclimatic specificities, as well as different land management practices. Nevertheless, several studies have shown the implications of land cover change for a number of environmental components, including: (i) climate regulation (Lambin and Helmut 2008); (ii) water cycle (Sterling et al. 2012); (iii) soil protection (Guerra et al. 2016); (iv) riverbank protection (Emberson 2017); (v) human pressure (Geldmann et al. 2014); (vi) habitat loss and fragmentation (Fardila et al. 2017; Li et al. 2018); (vii) biodiversity (Cardinale et al. 2012); among others.

Some land cover transitions are often interpreted as positive for biodiversity in a specific regional context (e.g., natural afforestation of grassland areas in the Amazon (Gunaratne et al. 2014)). However, the same transition (i.e., from grassland to forest) can be detrimental in a different region (e.g., (Farley and Kelly 2004; Nosetto et al. 2005; Stevens et al. 2017)). Regardless, land cover shifts affect the original state and, independently of the direction of change, the stability, composition and structure of ecosystems with potential implications for regional ecological processes and for associated biological communities (Jackson et al. 2000; Foley et al. 2007; Newbold et al. 2015). Stable ecosystems are capable of maintaining complex biological communities and reinforce ecological mechanisms at multiple scales (Tilman et al. 2014). This stability is particularly relevant for protected areas where long-term goals include protecting and maintaining high biodiversity and intact ecosystem processes (López et al. 2013).

Several studies underline the importance of protected areas to mitigate the adverse effects of human development on nature (e.g. Watson et al. 2014a; Small and Sousa 2016). However, ecosystem change, when motivated by land use and land cover change, often pressures protected areas, undermining their ability to fulfil their conservation objectives (DeFries et al. 2007; Nagendra 2008; Joppa and Pfaff 2011; Defries and Nagendra 2017). While protected areas mitigate the negative effects of human pressures, there is evidence that they are often extremely pressured on their borders. This pressure leaves them many times as conservation islands and, therefore, limits not only their potential to extend the effects of their conservation efforts to other areas (Hannah 2008) but also their global effectiveness on reducing the impacts of human pressures on biodiversity.

This study presents a temporally and spatially explicit estimation of global land cover change within 23 years (1992-2015) underlying the differences between global and regional estimates and the incidence of land cover change within and outside protected areas. Ultimately, we aim to identify past and current trends of change and stability and understand how these vary over space and time.

\section{Methods}

Change is here defined, for every location $i, j$, as the transformation from one land cover class to another in two consecutive moments in time. To identify and quantify change at the global scale, we used a recently published land cover dataset (ESA 2017) that includes a yearly spatial representation of land cover from 1992 to 2015 , at $300 \mathrm{~m}$ resolution. We opted for this dataset as it allows a continuous analysis of land-cover change at a high global resolution with a standardized classification and validation method (Li et al. 2016, 2018; Liu et al. 2018). Due to the temporal consistency in the land cover time series, achieved by using an innovative approach consisting in decoupling land cover mapping and change detection, this dataset allows for temporally explicit interpretations and to determine land cover change across space and time (ESA 2017). As for many land cover products at global scale, change detection can be underestimated under the current analysis (Jamali et al. 2015; Tsendbazar et al. 2015; Liu et al. 2018). This underestimation is related to the current limitations of land cover change detection at broader scales (Lunetta et al. 2004, 2006; Fuchs et al. 2015; Estes et al. 2018), but also with the inability to monitor and map land use change, decreasing the capacity to determine the 
impacts on biodiversity and ecosystems more effectively.

Land cover change was quantified at the global scale for each pair of years (i.e., 1992-1993, 1993-1994, etc.) producing a change map and an estimation of land cover change for every period. Global land cover change from 1992 to 2015 was estimated base on the accumulated change over time, once removed all spatial overlaps (Fig. 1). All the calculations of change were done using the original datasets with the full range of land cover classes. This accumulation implies that locations that changed once between 1992 and 2015 are interpreted as a land transformation in the same way that locations that changed three times. We recognise that these two locations would have different transformation dynamics, but here we focus on the assessment of overall land change independently of the frequency and direction of change. An important aspect of this analysis deals with the capacity of global change products to detect real changes in land cover (Hansen and Loveland 2012; Ban et al. 2015). Here, although some of the land cover classes present in the dataset are wide in scope (i.e., reducing detectability and the underestimation of ecosystem change), the thematic as well as spatial resolution offered allows for a consistent assessment across the globe. Global products often have issues regarding accuracy and detectability. Nevertheless, improvements over the last few years (Hansen et al. 2013), including the ones resulting in the dataset used here have provided an opportunity to assess the vulnerability of global ecosystems and direct policy and decision support (e.g., global forest watch; https://www.globalforestwatch.org).

We do not exclude that recent events (e.g., climaterelated) have dramatically contributed to changes in the poles. Nevertheless, considering the ability of the dataset used to capture these processes, we opted to exclude water and ice from the study area. Likewise, we also excluded the Arctic and Antarctic from the analysis.

For the assessment of protected areas, we used the 2017 version of the World Database on Protected Areas (WDPA 2017). This dataset was rasterized to the same spatial resolution as the land cover dataset (i.e., $300 \mathrm{~m}$ ) and used to produce two distinct masks: (i) the first containing all pixels within the borders of protected areas, which was used to estimate changes within their limits (from here onwards referred to as WDPA); and (ii) the second including all pixels within

GLOBAL

ESTIMATES

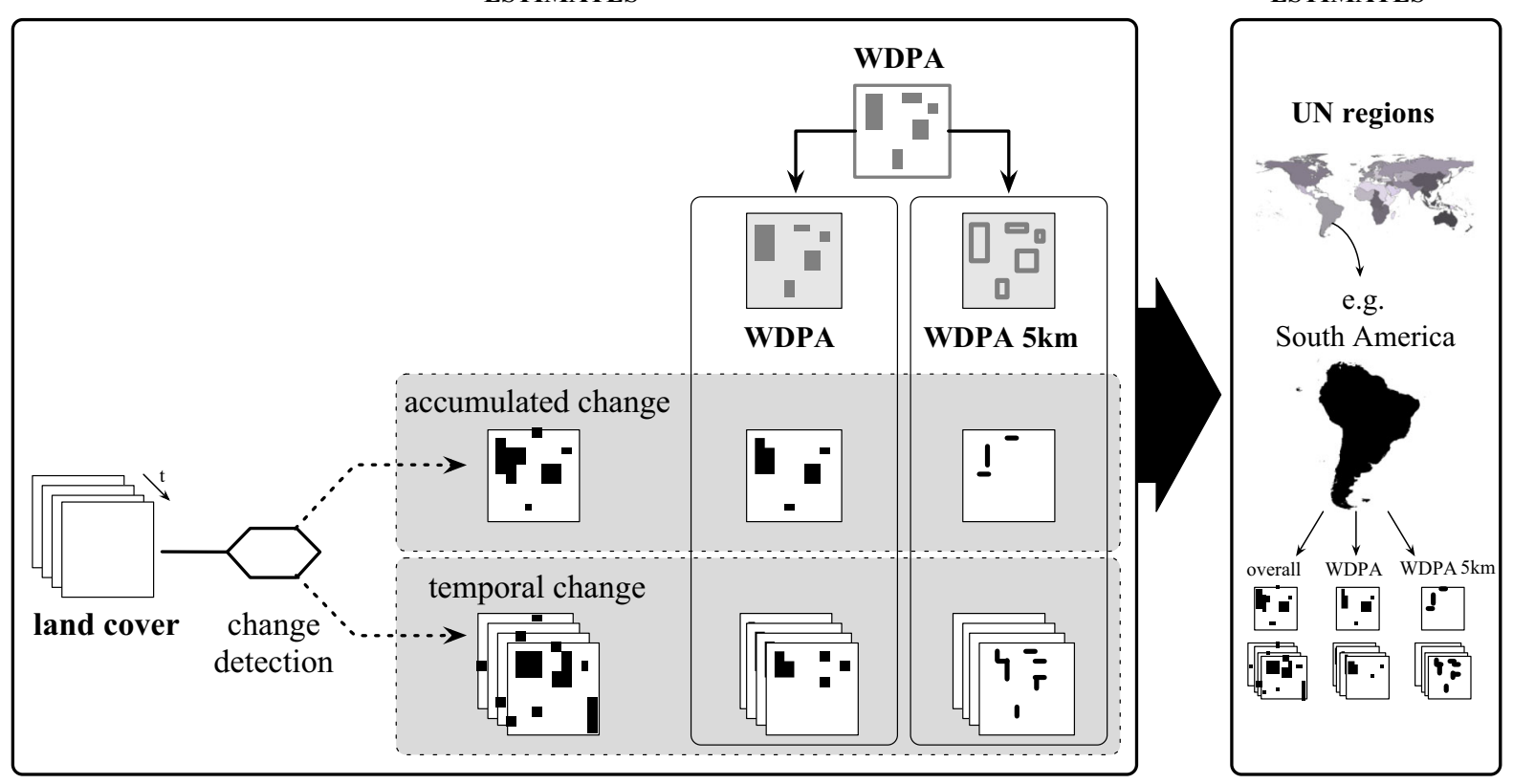

Fig. 1 Diagram representing the methodological procedures to assess accumulated and annual land cover change from 1992 to 2015 , at global and regional scales 
a radius of $\sim 5 \mathrm{~km}$ from all protected areas (i.e., excluding the actual protected area) (from here onwards referred to as WDPA $5 \mathrm{~km}$ ).

Due to the high number of classes in the land cover classification (35 classes), and although all the data were processed and analysed using the complete data and thematic resolution, results are presented in an aggregated form using a reclassified version of the original land cover classes (Table S1). This same reclassification was used to estimate which land cover classes were more affected through time and to produce transition matrices for every change period. Global estimates of land cover change were then disaggregated using the two WDPA masks described above and further by UN Region to investigate whether change patterns varied significantly over time, across these regions (Fig. 1).

Once we obtained a time series of change, an analysis of variance (ANOVA) was performed to test for significant differences across regions. Furthermore, we evaluated whether these time series showed a significant trend [either negative (deceleration of change) or positive (acceleration of change)] in the change estimated at the global scale and by region. Such analysis was done using a piecewise regression analysis for the three subsets used (Figure S1; total, WDPA and WDPA $5 \mathrm{~km}$ ), once earlier exploration revealed that in most cases there were breaks in the progression of change over time. This regression allowed us to detect significant breaks in the time series, and further determined the year in which these breakpoints were observed. Such investigation highlighted whether the positive or negative trends in land cover change emerged earlier/later in some regions rather than others, both inside and in the vicinity of protected areas. All the statistical analyses described before were performed using R 3.2.s (R Core Team 2016).

\section{Results}

Global change

Land cover change was estimated at the global scale to be $4.89 \%$ between 1992 and 2015 (Fig. 2a). This value refers to the accumulated change over the entire period and shows a higher concentration of these changes on the period before 2004. Globally these changes are mostly persistent (97.9\%), meaning that once converted from one land cover class to another this conversion lasts through time. Over time, we observed a significant increase $(\beta=0.06, \mathrm{t}$-value $=3.20$, $p$ value $<0.001)$ in the area that changed annually until 1999 after which there was a significant decrease $(\beta=-0.02, \mathrm{t}$-value $=-3.68, \mathrm{p}$-value $<0.001)$ until 2015 (Fig. 2b, Table S5, Figure S1). The highest change occurred between 1998 and 1999, whereas the lowest change was between 1993 and 1994. This lower value can be related to the lower classification accuracy registered in the first years of the time series (ESA 2017).

Using 1992 as a reference, the results highlight the land cover classes that were most affected by change (Fig. 2c). These include areas with a predominance of forest, shrubland and sparse vegetation, but also areas characterised by natural or cropland dominated mosaics. Nevertheless, these areas show different trajectories of change over time. While cropland and mosaic areas have proportionally increased between 1992 and 2015 (cropland $=2.04 \%$, natural mosaic $=$ $4.41 \%$, cropland mosaic $=7.08 \%$ ) both forest areas $(-1.52 \%)$ and shrubland $(-2.78 \%)$ have decreased globally within the period studied. These values, particularly the increase in mosaic areas, suggest an increase in the fragmentation of the landscape. It is also significant to see a global gain of $109.41 \%$ in urban areas, reflecting a higher conversion of cropland (representing $35 \%$ of the total urban increase) and herbaceous areas (representing $25 \%$ of the total urban increase) (Table S2).

When assessing change inside and outside protected areas, we found that in their vicinity (WDPA $5 \mathrm{~km}$ ) the percentage of change was $6.02 \%$. At the same time, although protected areas are known for their role in reducing the overall impacts of land change, there was still a significant percentage of change inside these areas $(3.91 \%)$. There was a higher percentage of change in the vicinity of the protected areas (i.e., WDPA $5 \mathrm{~km}$ ) than the total amount of change globally $(4.89 \%)$.

By comparison with the total global change, the land cover class most affected by change in the vicinity of protected areas (WDPA $5 \mathrm{~km}$ ) were mosaics with predominance of natural areas, shrublands and areas with sparse vegetation. In the case of mosaics with predominance of natural areas and shrublands, most of these changes were related to an 


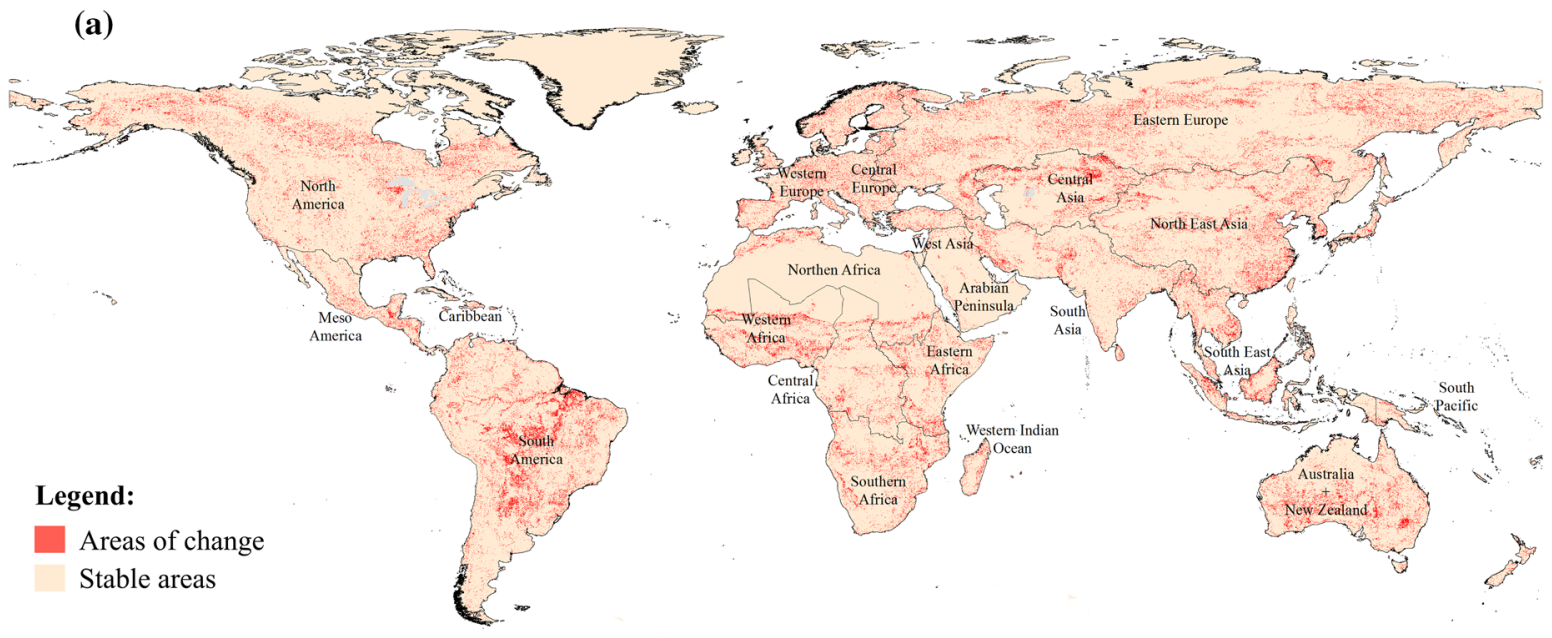

(b)

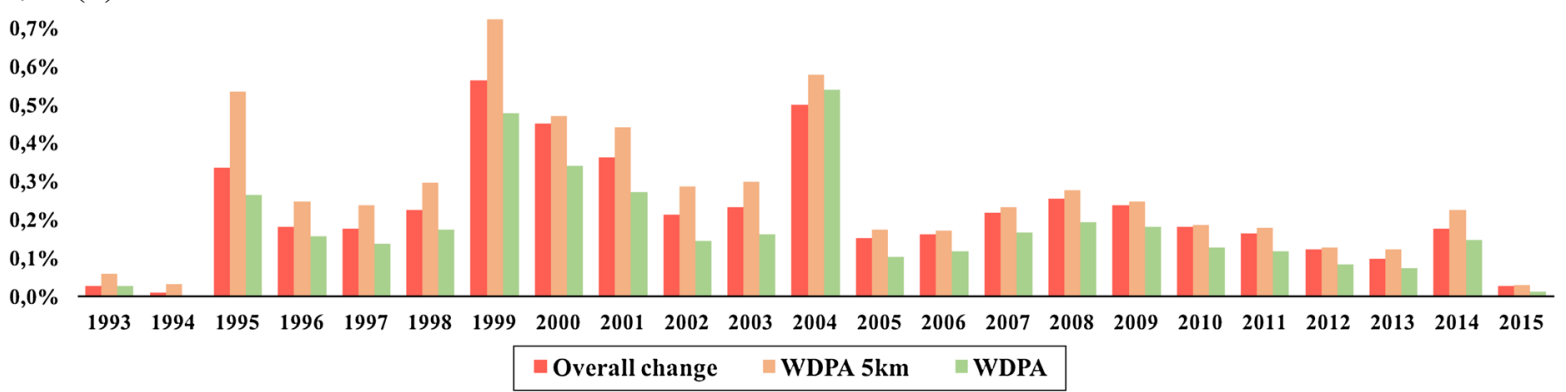

$10,0 \%$ (c)

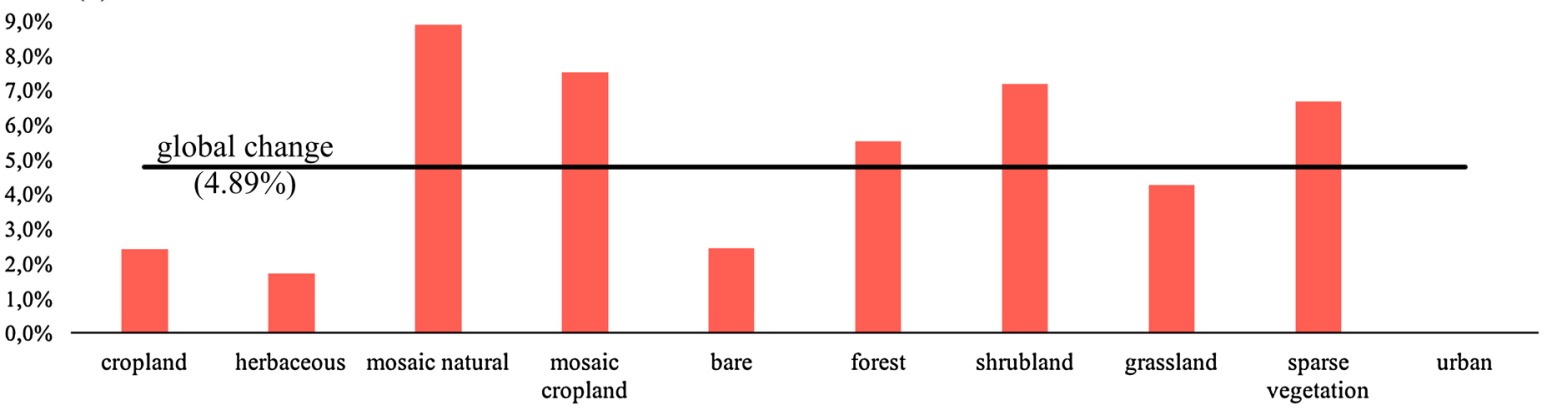

Fig. 2 Global land cover change between 1992 and 2015: a observed change and stability of land cover; $\mathbf{b}$ annual change for the global scale (total change), inside (WDPA) and within

increase in forest areas. Whilst, in the case of areas with sparse vegetation, the most predominant transitions were to grasslands, forest, and to mosaics with predominance of natural areas (Table S3 shows the percent changes that occurred per land cover class globally and across regions; Table S4 shows all proportional changes that occurred per land cover class globally and across regions). Our results also
$5 \mathrm{~km}$ of protected areas (WDPA $5 \mathrm{~km}$ ); $\mathbf{c}$ global incidence of change (1992-2015) having as reference the existing land cover in 1992

show that urbanization had a stronger effect near protected areas when compared with the total global values (respectively $2.05 \%$ and $0.54 \%$ by 2015) and even with the changes occurring inside protected areas, despite the increase of $151 \%$ that is explained by the relatively small representation of these areas inside protected areas $(0.04 \%$ in 1992 and $0.11 \%$ in 2015). 
Regional dynamics

When analysing the UN Regions, we found significant differences in the proportion of area that changed in total, inside (WDPA) and within $5 \mathrm{~km}$ of protected areas (WDPA $5 \mathrm{~km}$ ) (F-values of 5.95, 4.72, and 4.51, respectively, p-value $<0.001$; Fig. 3). Considering the complete period (1992-2015), the percentage of the total area that changed varied from a minimum of $0.87 \%$ in the Arabian Peninsula to a maximum of $8.90 \%$ in South East Asia, with an average of 5.24\% per region $[ \pm 0.41 \%$ standard error (s.e.)]. These

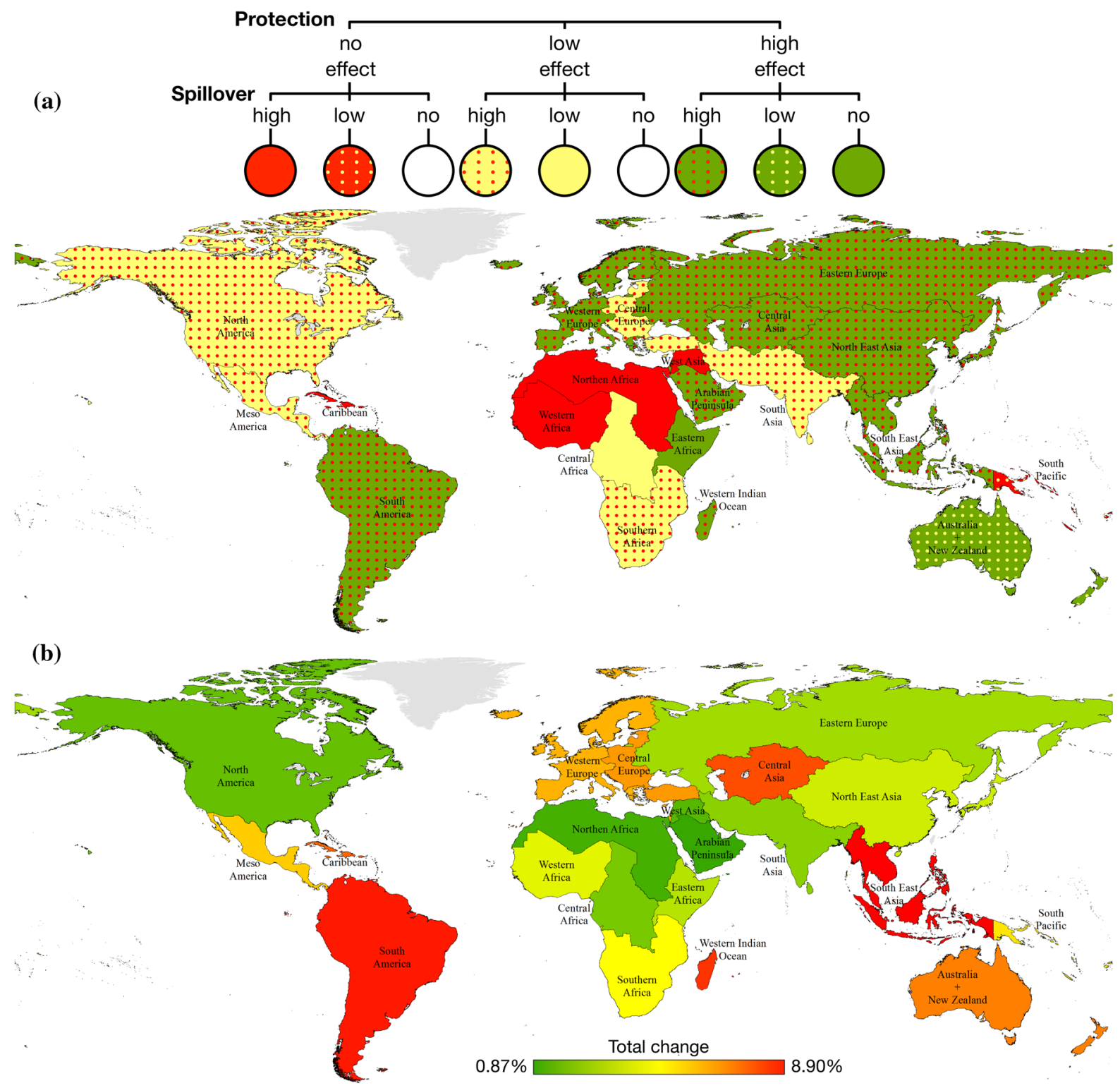

Fig. 3 Regional gradients of land cover change: a classified regional assessment according to the combination of protection (here represented by the ratio between WDPA and total land cover change) and spillover effects (here represented by the ratio between WDPA $5 \mathrm{~km}$ and total land cover change) [white circles represent empty classes and colors represent a gradient of effects from positive (green; e.g., in the case of high protection and no spillover) to negative (red; e.g., in the case of no effect from protection and high spillover); dots represent high (red), low (yellow) and no (green) spillover effect]; $\mathbf{b}$ heat map of the total regional land cover change, ranging from $0.87 \%$ (green) to $8.90 \%$ (red) (for more details see Table S3). Grey areas represent areas outside of the scope of the analysis. (Color figure online) 
changes were mainly motivated by losses in forest cover, shrublands and sparse vegetation cover and gains in herbaceous areas, natural mosaics and urban areas. The results also show an increase of croplands and cropland dominated mosaics particularly in African regions and in South America. Although general trajectories can be determined, these vary across regions and continents (Table S4), e.g., there is higher urbanisation in Europe, particularly in Central and Western Europe, and greater deforestation in Latin America, particularly in South America.

Across regions, inside protected areas, there was an average change of $5.46 \%$ ( $\pm 0.49 \%$ s.e.), but this percentage increased to $6.39 \%$ ( $\pm 0.51 \%$ s.e.) when outside protected areas. Both minimum values for inside and outside protected areas were observed in the Arabian Peninsula. Maximum values of land cover change inside protected areas were observed for Mashriq (11.10\%, mainly motivated by losses in sparse vegetation and gains in bare areas, herbaceous cover and croplands) and outside in the Western Indian Ocean region $(11.46 \%$, primarily driven by the loss in cropland dominated mosaics and the gain in natural mosaics together with forests and shrublands).

On average, changes occurring inside protected areas were lower than on its boundaries (ratio of $0.89 \pm 0.11$ s.e.), whereas changes within $5 \mathrm{~km}$ from protected areas (WDPA $5 \mathrm{~km}$ ) were higher than the total changes (ratio of $1.27 \pm 0.06$ s.e.). However, such results varied considerably across regions (Table 1; Fig. 3). For example, while the Arabian Peninsula showed the lowest ratio $(0.20)$ regarding WDPA change, it also showed the maximum value for the ratio between WDPA $5 \mathrm{~km}$ and total change (2.05), suggesting a significant pressure on the boundaries of the existing protected areas. These spillover effects were also observed in a number of other regions with low change inside protected (high protection effect), such as Western and Eastern Europe, and South America. The Mashriq region showed the highest ratio for inside/outside (2.91).

We found a strong positive relationship $\left(\mathrm{r}^{2}=0.78\right.$, $\beta=1.10, p$-value $<0.001$ ) between total change and change within $5 \mathrm{~km}$ of protected areas across UN Regions (Fig. 4a). This relationship shows that regions with high proportional change also showed a higher proportional change in the vicinity of protected areas (WDPA $5 \mathrm{~km}$ ). Conversely, we found a weak relationship between total change and change observed inside these areas $\left(\mathrm{r}^{2}=0.26, \beta=0.62\right.$, p-value $=0.02)($ Fig. $4 b)$, as well as between inside and outside $\left(r^{2}=0.23, \beta=0.47, p\right.$-value $\left.=0.03\right)$. Such results further support earlier findings that although protected areas seem to be effective in preventing land cover change, their vicinities are under great pressure to change.

\section{Discussion}

The study of ecosystem change has long captured the attention of both researchers, practitioners and decision-makers (Joppa et al. 2016). Although ecosystem change research can and has addressed more nuanced functional changes, here ecosystem change is portrayed as consequence of land cover change and, therefore, as a more or less drastic change in ecosystem properties. It is debatable that specific land cover transitions in a given region are beneficial (e.g. successional transitions) or detrimental (e.g. deforestation) for ecosystems and biodiversity. Nevertheless, the discussion of ecosystem change (through land cover change) extends beyond this topic by assuming that any change results in consequences (positive or negative) for ecosystems and biodiversity conservation management. Globally, our results show an accumulated total land cover change of $4.89 \%$. Although relatively small, when these results are further disaggregated, they exhibit higher variation (regionally between 0.87 and $8.90 \%$, and nationally between 0 and 32.5\%), which is in line with what other studies show about land change (e.g. Falcucci et al. 2007; Gerard et al. 2010; Hansen et al. 2013), giving us a higher confidence level about the general outcomes. While these numbers are impressive, these may be underestimated due to broad definition of land cover classes from the ESA dataset. This broad definition includes for example broad mosaic classes with rather large variation in forest cover. Therefore, changes that do not exceed the class boundaries go unnoticed which may result in an underestimation of ecosystem change.

Recent studies (e.g. Gray et al. 2016; Hellwig et al. 2019) suggested that protected areas reduce the pressure from multiple drivers, including land cover change. Our results partially support this statement. We showed that, with smaller incidence, protected areas are also subject to change with comparable 
Table 1 Ratio between proportional change inside (WDPA) and outside (WDPA $5 \mathrm{~km}$ ) conservation areas from 1992 to 2015 , and between these and total change across UN Regions, and globally

\begin{tabular}{|c|c|c|c|}
\hline Region & WDPA/WDPA 5 km & WDPA $5 \mathrm{~km} /$ total & WDPA/total \\
\hline Central Africa & 0.98 & 0.99 & 0.97 \\
\hline Eastern Africa & 0.99 & 0.92 & 0.91 \\
\hline Northern Africa & 0.74 & 1.90 & 1.39 \\
\hline Southern Africa & 0.84 & 1.22 & 1.03 \\
\hline Western Africa & 0.93 & 1.34 & 1.25 \\
\hline Western Indian Ocean & 0.56 & 1.61 & 0.90 \\
\hline Australia + New Zealand & 0.91 & 0.99 & 0.91 \\
\hline Central Asia & 0.75 & 1.05 & 0.79 \\
\hline North East Asia & 0.60 & 1.32 & 0.79 \\
\hline South Asia & 0.79 & 1.29 & 1.02 \\
\hline South East Asia & 0.85 & 1.11 & 0.94 \\
\hline South Pacific & 1.20 & 1.01 & 1.21 \\
\hline Central Europe & 0.95 & 1.05 & 1.00 \\
\hline Eastern Europe & 0.77 & 1.21 & 0.93 \\
\hline Western Europe & 0.83 & 1.11 & 0.92 \\
\hline Caribbean & 0.94 & 1.35 & 1.27 \\
\hline Meso America & 0.70 & 1.48 & 1.03 \\
\hline South America & 0.52 & 1.19 & 0.61 \\
\hline North America & 0.81 & 1.21 & 0.97 \\
\hline Arabian Peninsula & 0.20 & 2.05 & 0.40 \\
\hline Mashriq & 2.91 & 1.29 & 3.76 \\
\hline Global & 0.65 & 1.23 & 0.80 \\
\hline
\end{tabular}

evolution to the one identified at the global scale (Fig. 2b). Our study quantified the difference between inside and outside protected areas but, more importantly, the potential spillover effects. Our analysis revealed that protected areas, although safeguarding important biodiversity and ecosystem values within their borders (i.e., low change, higher stability), were still subject to high pressure in their vicinity even when compared with the total amount of change. Over time, this can have severe impacts and uphold relevant drawbacks to conservation efforts as these areas have the potential to become islands within their ecological systems.

This border issue is more relevant for Northern Africa and the Arabian Peninsula, although these represent two different states regarding protection effects. While Northern African protected areas are significantly affected by change, even when compared with the overall regional change, protected areas in the Arabian Peninsula show a substantial effect of protected areas in reducing land cover change despite, overall, both regions showing a low change rate. Still, other regions with higher rate of change (Table S3) presented similar patterns of high border pressure with low (e.g., Western Africa, Caribean) and high protected area effects (e.g., South East Asia, South America).

Our results highlight the positive influence of protected areas in halting ecosystem change (Table 1, e.g. South America) and the opportunity, at the global scale, that these regions offer to expand the current benefits of protected areas. In fact, $86 \%$ (18 in 21) of the regions assessed showed more pressure next to protected areas than the total global change (Fig. 3). With a few exceptions (i.e., South Pacific and Mashriq with a higher percentage of change inside protected areas and Central Africa with no net effects), our regional results showed an overall positive influence of protected areas in reducing the dynamics of land cover change. These exceptions may result from current conservation policies and regulations (Watson et al. 2014b) but may also be a consequence of lack of enforcement power resulting from internal national crises (e.g., war zones) or lack of governmental capacity (Adenle et al. 2015). This is shown by our results for Central Africa where there is almost no 
(a)

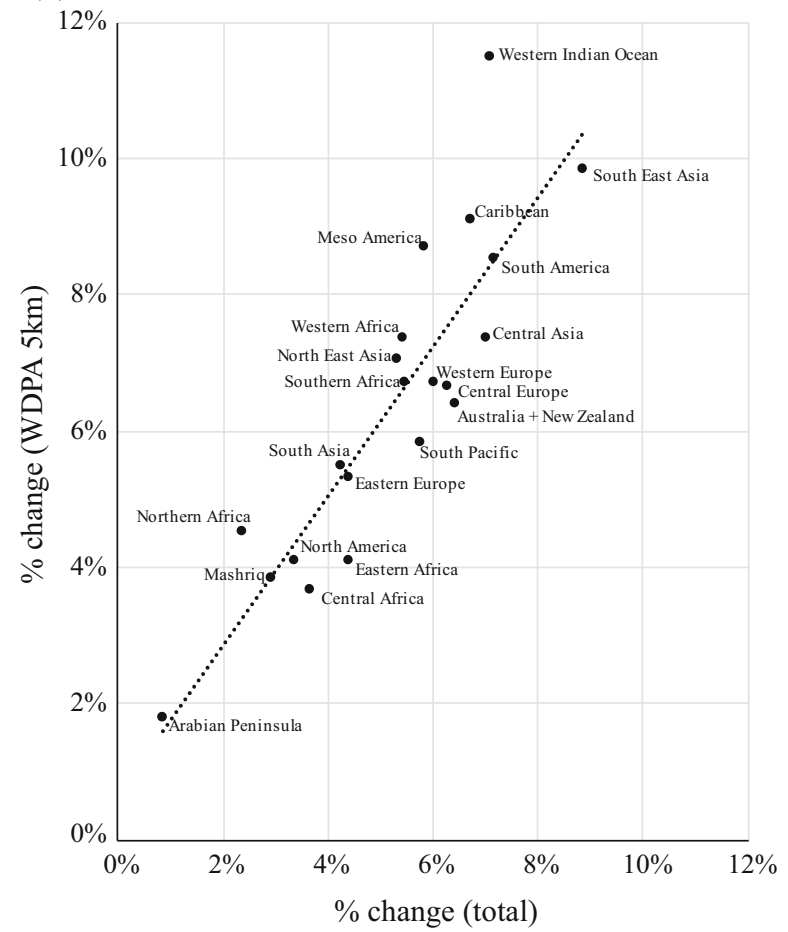

Fig. 4 Correlation at regional level of a total land cover change and change occurring within $5 \mathrm{~km}$ of existing protected areas; and b total land cover change and change occurring inside

difference between the percentage of change inside and outside protected areas within the region.

For regions like South America, assuming current rates of change, expanding current protected areas, and/or creating new ones, can have a more lasting effect in halting land cover change than in regions like Central and Eastern Africa where this effect is not so clear. Furthermore, the existence of spillover effects should be integrated in the design of protection strategies as to avoid a simple displacement of land cover change. This is particularly important for megadiverse regions where small changes in the protection strategy may lead to significant results for conservation.

Overall, these results support the differentiation of regional conservation policies as regions showed significant differences between themselves. This need for differentiation is even more relevant when framed within current global conservation targets (e.g., Aichi targets 5, that includes a call to halt the rate of loss of all natural habitats, including forests, and 12, that includes a call to prevent the extinction of known (b)

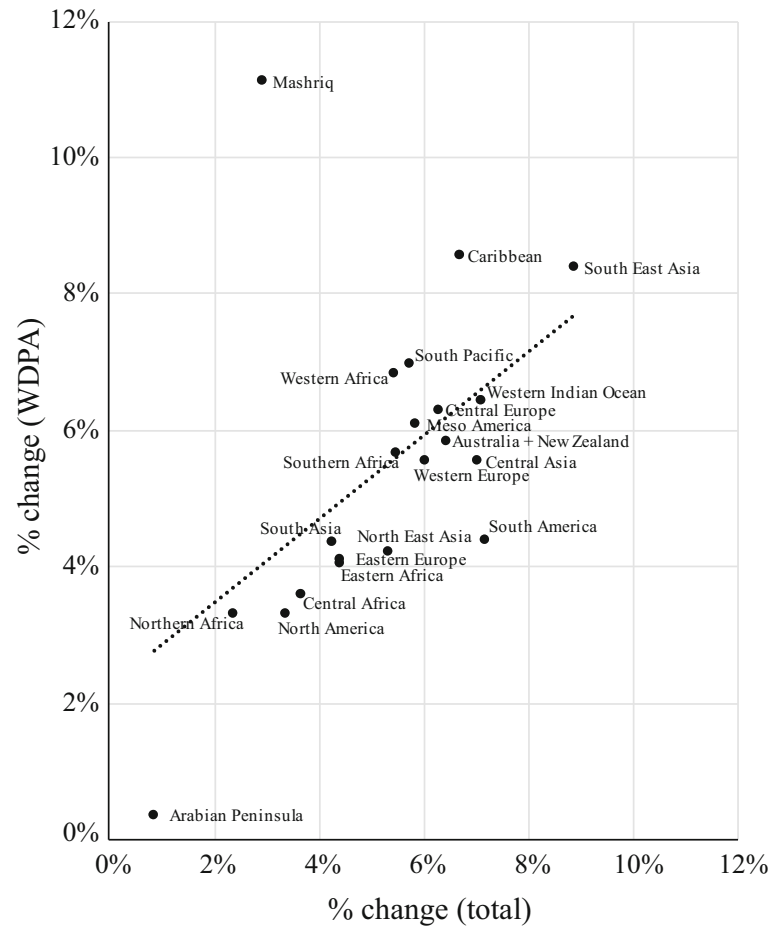

protected areas. Dotted line represents a linear regression $\left(r^{2}=0.78\right.$, and $r^{2}=0.26$, respectively) between the two covariates

threatened species). In fact, to successfully contribute to these targets, new protected areas (i.e., in the scope of Aichi target 11, that includes a call to increase global protected area coverage) must be strategically located (Baldi et al. 2017) not only considering the biodiversity and ecosystem values that they aim to preserve but also the effectivity of current conservation to halt ecosystem change. In the scope of the Sustainable Development Goals and the redefinition of the global nature conservation challenges, policy makers should focus their attention on more integrative views where multiple views of the concerns a protected area (e.g., connectivity, ecosystem change, internal and exogenous pressures and impacts) are included and not only their extent. Using platforms like the Digital Observatory for Protected Areas (DOPA) is a first step in the right direction, but it has to be complemented by a clear policies that use multiple indicators to assess the outcomes of nature conservation around the world.

At the same time, it is necessary to flag critical regions where conservation action shows signs of 
being severely hampered (Watson et al. 2014b). These protected areas and regions, deserve not only particular attention from the international community but also from national authorities to monitor and assess potential problems within their conservation strategy, resources and implementation capacity. It is also necessary that governments and conservation management agencies pay attention to areas surrounding protected areas and, when needed, develop specific actions to reduce impacts and pressure from land cover change.

Global initiatives like the World Database on Protected Areas (WDPA 2017) and the Digital Observatory for Protected Areas (Dubois et al. 2016) are already allowing for a better understanding and flagging of critical situations by assessing protected areas from a multidimensional perspective. Additionally, our results show that improving the effectiveness of conservation policies to halt ecosystem change needs to go further than establishing incremental goals for protected area coverage. Recent research, including for other realms (e.g., Gill et al. 2017) already shows that a special focus on actual capacity and management activities is needed when evaluating current protected area coverage and outcomes.

Acknowledgements $\mathrm{CG}$ is supported by the European Union's Horizon 2020 research and innovation programme under Grant Agreement No 641762-ECOPOTENTIAL project ("Improving future ecosystem benefits through earth observations"). IMDR has received funding from the European Union's Horizon 2020 research and innovation programme under the Marie Sklodowska-Curie Grant Agreement No 703862.

Open Access This article is distributed under the terms of the Creative Commons Attribution 4.0 International License (http:// creativecommons.org/licenses/by/4.0/), which permits unrestricted use, distribution, and reproduction in any medium, provided you give appropriate credit to the original author(s) and the source, provide a link to the Creative Commons license, and indicate if changes were made.

\section{References}

Adenle AA, Stevens C, Bridgewater P (2015) Global conservation and management of biodiversity in developing countries: an opportunity for a new approach. Environ Sci Policy 45:104-108
Baldi G, Texeira M, Martin OA, Grau HR, Jobbágy EG (2017) Opportunities drive the global distribution of protected areas. PeerJ 5:e2989

Ban Y, Gong P, Giri C (2015) Global land cover mapping using Earth observation satellite data: recent progresses and challenges. ISPRS J Photogramm Remote Sens 103:1-6

Benjamin K, Domon G, Bouchard A (2005) Vegetation composition and succession of abandoned farmland: effects of ecological, historical and spatial factors. Landscape Ecol 20:627-647

Cardinale BJ, Duffy JE, Gonzalez A, Hooper DU, Perrings C, Venail P, Narwani A, Mace GM, Tilman D, Wardle DA, Kinzig AP, Daily GC, Loreau M, Grace JB, Lariguaderie A, Srivastava D, Naeem S (2012) Biodiversity loss and its impact on humanity. Nature 486:59-68

Defries R, Nagendra H (2017) Ecosystem management as a wicked problem. Science 80:265-270

DeFries R, Hansen A, Turner BL, Reid R, Liu J (2007) Land use change around protected areas: management to balance human needs and ecological function. Ecol Appl 17:1031-1038

Dubois G, Bastin L, Bertzky B, Mandrici A, Conti M, Saura S, Cottam A, Battistella L, Martínez-López J, Boni M, Graziano M (2016) Integrating multiple spatial datasets to assess protected areas: lessons learnt from the digital observatory for protected areas (DOPA). ISPRS Int J GeoInform 5:242

Emberson R (2017) Deforestation: accelerating riverbank erosion. Nat Geosci 10:328

ESA (2017) Land cover newsletter: release of a 1992-2015 time series of annual global land cover maps at $300 \mathrm{~m}$

Estes L, Chen P, Debats S, Evans T, Ferreira S, Kuemmerle T, Ragazzo G, Sheffield J, Wolf A, Wood E, Caylor K (2018) A large-area, spatially continuous assessment of land cover map error and its impact on downstream analyses. Glob Change Biol 24:322-337

Falcucci A, Maiorano L, Boitani L (2007) Changes in landuse/land-cover patterns in Italy and their implications for biodiversity conservation. Landscape Ecol 22:617-631

Fardila D, Kelly LT, Moore JL, McCarthy MA (2017) A systematic review reveals changes in where and how we have studied habitat loss and fragmentation over 20 years. Biol Conserv 212:130-138

Farley KA, Kelly EF (2004) Effects of afforestation of a páramo grassland on soil nutrient status. For Ecol Manage 195:281-290

Foley JA, Defries R, Asner GP, Barford C, Bonan G, Carpenter SR, Chapin FS, Coe MT, Daily GC, Gibbs HK, Helkowski JH, Holloway T, Howard EA, Kucharik CJ, Monfreda C, Patz JA, Prentice IC, Ramankutty N, Snyder PK (2005) Global consequences of land use. Science 309:570-574

Foley JA, Asner GP, Costa MH, Coe MT, Gibbs HK, Howard EA, Olson S, Patz J, Ramankutty N, Snyder P, Foley JA, Asner GP, Costa MH, Coe MT, Defries R, Gibbs HK, Howard EA, Olson S, Patz J, Ramankutty N, Snyder P (2007) Amnazonia revealed: forest degradation and loss of ecosystem goods and services in the Amazon Basin. Front Ecol Environ 5:25-32

Fuchs R, Herold M, Verburg PH, Clevers JGPW, Eberle J (2015) Gross changes in reconstructions of historic land 
cover/use for Europe between 1900 and 2010. Glob Change Biol 21:299-313

Geldmann J, Joppa LN, Burgess ND (2014) Mapping change in human pressure globally on land and within protected areas. Conserv Biol 28:1604-1616

Gerard F, Petit S, Smith G, Thomson A, Brown N, Manchester S, Wadsworth R, Bugar G, Halada L, Bezák P, Boltiziar M, Badts E, Halabuk A, Mojses M, Petrovic F, Gregor M, Hazeu G, Mücher CA, Wachowicz M, Huitu H, Tuominen S, Köhler R, Olschofsky K, Ziese H, Kolar J, Sustera J, Luque S, Pino J, Pons X, Roda F, Roscher M, Feranec J (2010) Land cover change in Europe between 1950 and 2000 determined employing aerial photography. Prog Phys Geogr 34:183-205

Gill DA, Mascia MB, Ahmadia GN, Glew L, Lester SE, Barnes M, Craigie I, Darling ES, Free CM, Geldmann J, Holst S, Jensen OP, White AT, Basurto X, Coad L, Gates RD, Guannel G, Mumby PJ, Thomas H, Whitmee S, Woodley S, Fox HE (2017) Capacity shortfalls hinder the performance of marine protected areas globally. Nature 543:665-669

Gray CL, Hill SLL, Newbold T, Hudson LN, Börger L, Contu S, Hoskins AJ, Ferrier S, Purvis A, Scharlemann JPW (2016) Local biodiversity is higher inside than outside terrestrial protected areas worldwide. Nat Commun 7:12306

Guerra C, Metzger MJ, Maes J, Pinto-Correia T (2016) Policy impacts on regulating ecosystem services: looking at the implications of 60 years of landscape change on soil erosion prevention in a Mediterranean silvo-pastoral system. Landscape Ecol 31:271-290

Gunaratne AMTA, Gunatilleke CVS, Gunatilleke IAUN, Madawala HMSP, Burslem DFRP (2014) Overcoming ecological barriers to tropical lower montane forest succession on anthropogenic grasslands: synthesis and future prospects. For Ecol Manage 329:340-350

Hannah L (2008) Protected areas and climate change. Ann NY Acad Sci 1134:201-212

Hansen MC, Loveland TR (2012) A review of large area monitoring of land cover change using Landsat data. Remote Sens Environ 122:66-74

Hansen MC, Potapov PV, Moore R, Hancher M, Turubanova SA, Tyukavina A, Thau D, Stehman SV, Goetz SJ, Loveland TR, Kommareddy A, Egorov A, Chini L, Justice CO, Townshend JRG (2013) High-resolution global maps of 21st-century forest cover change. Science 342:850-853

Hellwig N, Walz A, Markovic D (2019) Climatic and socioeconomic effects on land cover changes across Europe: does protected area designation matter? PLoS ONE 14:e0219374

Jackson RB, Schenk HJ, Jobbágy EG, Canadell J, Colello GD, Dickinson RE, Field CB, Friedlingstein P, Heimann M, Hibbard K, Kicklighter DW, Kleidon A, Neilson RP, Parton WJ, Sala OE, Sykes MT (2000) Belowground consequences of vegetation change and their treatment in models. Ecol Appl 10:470-483

Jamali S, Jönsson P, Eklundh L, Ardö J, Seaquist J (2015) Detecting changes in vegetation trends using time series segmentation. Remote Sens Environ 156:182-195

Joppa LN, Pfaff A (2011) Global protected area impacts. Proc R Soc B 278:1633-1638
Joppa LN, Bailie JEM, Robinson JG (2016) Protected areas: are they safeguarding biodiversity?. Wiley, New York

Lambin EF, Helmut JG (2008) Land-use and land-cover change: local processes and global impacts. Springer, Berlin

Levine NM, Zhang K, Longo M, Baccini A, Phillips OL, Lewis SL, Alvarez-Dávila E, Segalin de Andrade AC, Brienen RJW, Erwin TL, Feldpausch TR, Monteagudo Mendoza AL, Nuñez Vargas P, Prieto A, Silva-Espejo JE, Malhi Y, Moorcroft PR (2016) Ecosystem heterogeneity determines the ecological resilience of the Amazon to climate change. Proc Natl Acad Sci 113:793-797

Li W, Ciais P, MacBean N, Peng S, Defourny P, Bontemps S (2016) Major forest changes and land cover transitions based on plant functional types derived from the ESA CCI Land Cover product. Int J Appl Earth Obs Geoinf 47:30-39

Li W, Macbean N, Ciais P, Defourny P, Lamarche C, Bontemps S, Houghton RA, Peng S (2018) Gross and net land cover changes in the main plant functional types derived from the annual ESA CCI land cover maps (1992-2015). Earth Syst Sci Data 10:219-234

Liu X, Yu L, Sia Y, Zhang C, Lu H, Yu C, Gong P (2018) Identifying patterns and hotspots of global land cover transitions using the ESA CCI land cover dataset. Remote Sens Lett 9:972-981

López D, Brizuela M, Willems P, Aguiar M, Siffredi G, Bran D (2013) Linking ecosystem resistance, resilience, and stability in steppes of North Patagonia. Ecol Indic 24:1-11

Lunetta RS, Johnson DM, Lyon JG, Crotwell J (2004) Impacts of imagery temporal frequency on land-cover change detection monitoring. Remote Sens Environ 89:444-454

Lunetta RS, Knight JF, Ediriwickrema J, Lyon JG, Worthy LD (2006) Land-cover change detection using multi-temporal MODIS NDVI data. Remote Sens Environ 105:142-154

Nagendra H (2008) Do parks work? Impact of protected areas on land cover clearing. AMBIO J Hum Environ 37:330-337

Newbold T, Hudson LN, Hill SLL, Contu S, Lysenko I, Senior RA, Börger L, Bennett DJ, Choimes A, Collen B, Day J, De Palma A, Díaz S, Echeverria-Londoño S, Edgar MJ, Feldman A, Garon M, Harrison MLK, Alhusseini T, Ingram DJ, Itescu Y, Kattge J, Kemp V, Kirkpatrick L, Kleyer M, Correia DLP, Martin CD, Meiri S, Novosolov M, Pan Y, Phillips HRP, Purves DW, Robinson A, Simpson J, Tuck SL, Weiher E, White HJ, Ewers RM, Mace GM, Scharlemann JPW, Purvis A (2015) Global effects of land use on local terrestrial biodiversity. Nature 520:45-50

Nosetto MD, Jobbágy EG, Paruelo JM (2005) Land-use change and water losses: the case of grassland afforestation across a soil textural gradient in central Argentina. Glob Chang Biol 11:1101-1117

Pereira HM, Navarro LM, Martins IS (2012) Global biodiversity change: the bad, the good, and the unknown. Annu Rev Environ Resour 37:25-50

R Core Team (2016) R: A language and environment for statistical computing

Small C, Sousa D (2016) Humans on Earth: global extents of anthropogenic land cover from remote sensing. Anthropocene 14:1-33

Sterling SM, Ducharne A, Polcher J (2012) The impact of global land-cover change on the terrestrial water cycle. Nat Clim Change 3:385-390 
Stevens N, Lehmann CER, Murphy BP, Durigan G (2017) Savanna woody encroachment is widespread across three continents. Glob Chang Biol 23:235-244

Tilman D, Isbell F, Cowles JM (2014) Biodiversity and ecosystem functioning. Annu Rev Ecol Evol Syst 45:471-493

Tsendbazar NE, de Bruin S, Fritz S, Herold M (2015) Spatial accuracy assessment and integration of global land cover datasets. Remote Sens 7:15804-15821

Watson JEM, Dudley N, Segan DB, Hockings M (2014a) The performance and potential of protected areas. Nature 515:67-73
Watson SJ, Luck GW, Spooner PG, Watson DM (2014b) Landuse change: incorporating the frequency, sequence, time span, and magnitude of changes into ecological research. Front Ecol Environ 12:241-249

WDPA (2017) Word database on protected areas [WWW Document]. URL http://www.unep-wcmc.org/wdpa/. Accessed 5 Jan 2017

Publisher's Note Springer Nature remains neutral with regard to jurisdictional claims in published maps and institutional affiliations. 